$\pm$

\title{
LA CONVERGENCIA INTERNA DE LAS AYUDAS DE LA PAC: AYER, HOY Y MAÑANA Tomás García Azcárate*
}

\author{
*, Vice-Director del Instituto de Economía, Geografía y Demografía (IEGD-CSIC) e investigador \\ asociado del CEIGRAM, Madrid, E-mail: tomasgarciaazcarate@gmail.com
}

\begin{abstract}
Resumen: El tema de la convergencia interna de las ayudas de la PAC es uno de los temas claves, tanto del periodo transitorio entre la PAC 2014-2020 y la futura PAC como para esta nueva PAC. La Comunicación realiza primero un análisis histórico de la génesis y de la evolución de dichas ayudas, A continuación, a la luz de los desarrollos históricos señalados en la primera parte, aborda los debates actuales intentando aportar unos elementos de análisis y raciocinio en un debate que se ha vuelto eminentemente político y emocional
\end{abstract}

Metodológicamente, la Comunicación se basa en la experiencia personal del autor, actor y espectador de primera fila de gran parte de la evolución analizada, en numerosas entrevistas y contactos realizados y en múltiples reuniones en las que ha participado, junto con una revisión bibliografía, tanto académica como de noticias de prensa para los temas de actualidad.

Palabras claves: Política Agraria Comun, convergencia interna

\section{Introducción}

El tema de la convergencia interna de las ayudas de la PAC es uno de los temas claves, tanto del periodo transitorio entre la PAC 2014-2020 y la futura PAC como para esta nueva PAC. La Comunicación realiza primero un repaso histórico de la génesis y de la evolución de dichas ayudas. Luego presenta brevemente la aplicación en España del desacoplamiento aprobado en el año 2003, tanto en España como en los restantes Estados miembros para terminar abordando los debates actuales intentando aportar unos elementos de análisis y raciocinio en un debate que se ha vuelto eminentemente político y emocional. En la tercera y última parte, se resumen las conclusiones parciales anteriores y se presentan unas reflexiones finales sobre la evolución futura del debate.

Metodológicamente, la Comunicación se basa en la experiencia personal del autor, actor y espectador de primera fila de gran parte de la evolución analizada, en numerosas entrevistas y contactos realizados y en múltiples reuniones en las que ha participado, junto con una revisión bibliografía, tanto académica como de noticias de prensa para los temas de actualidad..

\section{Un breve repaso histórico}

Las futuras "ayudas directas para la sostenibilidad" previstas por la próxima PAC son las nietas de las ayudas compensatorias por hectárea o cabeza de ganado de la reforma Mac Sharry en el año 1992. En aquel año, las ayudas a la hectárea se calcularon por Estado miembro en base a la media de los rendimientos cerealistas 1989-1991. Cada país redistribuyo esta cifra resultante como le convino mejor. Dinamarca, por ejemplo, considero todo el país como una única región, hizo la convergencia interna total desde los inicios; otros como España diferenciaron por comarcas, entre secano y regadío y entre maíz y el resto de los cereales, para que la compensación calculada fuera lo más ajustada a la realidad agronómica del momento.

Como la bajada de los cereales iba a tener como consecuencia un aumento de la competitividad de la carne de porcino y aviar, los "cereales con patas", y para mantener el equilibrio con la carne de vacuno, para el ganado vacuno se aprobaron dos ayudas, una a la vaca nodriza y otra también para el cebo de ganado, a pesar de que él también iba a sacar provecho de la baja de los costes de la alimentación.

Hasta el año 2003, en sucesivas reformas, la Unión Europea profundizó en este camino, tanto con el Agenda 2000 como en distintas reformas sectoriales como las de las frutas y hortalizas, el sector lácteo o el aceite de oliva.

En los años 2003 y 2004, lo que iba a ser una "revisión a medio plazo" se transformó en la segunda gran reforma de la PAC, con el "desacoplamiento" de las ayudas de la producción y la generalización de la condicionalidad, principalmente medio-ambiental y del bienestar animal. El Consejo de Ministros no creyó 
oportuno en aquel momento poner el respeto de las leyes que protegen a los trabajadores al mismo nivel que la protección de los animales, a pesar de la propuesta inicial de la Comisión.

En el 2004, ya las referencias de cálculo inicial tenían más de 10 años. En Europa se abrió poco a poco un doble debate en torno a la convergencia, la externa entre los valores medios de ayuda de cada Estado miembro y la interna entre los agricultores de un mismo Estado miembro. La realidad productiva entre tanto había cambiado y tenía poco sentido que dos agricultores de una misma región que cultivasen lo mismo tuvieran ayudas distintas a la hectárea en base al mapa productivo de finales de los 90 .

El acuerdo sobre la PAC 2014-2020 es la penúltima etapa de este periplo (CE, 2015). La regla general es que las ayudas deben ser idénticas en cada una de las regiones del país. Dos derogaciones están previstas: la primera para autorizar una transición hacia la convergencia total para el 2019, la segunda para aquellos Estados miembros que prefieren una convergencia parcial. El objetivo a conseguir entonces para el año 2019 es que ningún agricultor debería recibir menos del 60\% de su media regional aunque hay un mecanismo de protección para limitar las pérdidas de los que tienen mayor dotación, y es que está no puede bajar menos del $30 \%$.

\section{La aplicación en España}

El gobierno español tuvo muy claro desde el principio de la negociación que su objetivo era que la aplicación final del nuevo sistema de ayudas debía mantener lo más posible el estatus quo para minimizar los cambios para los agricultores y los trasvases presupuestarios entre regiones. La verdad es que consiguió plenamente su objetivo.

España no solo ha escogido la convergencia parcial sino que ha realizado una interpretación amplia del término "región". Partiendo de las comarcas agrarias, teniendo en cuenta la superficie en cultivos herbáceos del secano y del regadío y la de cultivos leñosos, ha reconocido 50 regiones que son una amalgama de trozos de dichas comarcas. La relación entre la media regional más baja $(60 €)$ y la más alta (1430€) es de 1:24 (Ruiz, 2019) pero entre beneficiarios es de 1:160.000 (Miranda, 2021). Por poner el ejemplo de un solo cultivo, el del olivar, y tomando los ejemplos difundidos por la Consejería de Agricultura de Andalucía, un olivarero del bajo Guadalquivir podría recibir $1.294 €$ por hectárea y uno de Cazorla $2.063 €$. Mientras tanto en Castilla la Mancha las ayudas, también para los olivareros, están entre 100 y $150 € /$ ha.

\section{El debate actual}

Lo que estas cifras ponen en entredicho es el carácter realmente desacoplado de las ayudas de la PAC tal y como estaban diseñadas hasta ahora. Los Estados Unidos han puesto en duda el carácter desacoplado del sistema actual de ayudas directas, instaurando un arancel suplementario a sus importaciones de aceitunas negras españolas. La Unión Europea ha llevado el tema delante de la Organización Mundial del Comercio solicitando la creación de un panel específico al respecto el 20 de enero de $2019^{9}$.

Lo que está en juego es la clasificación de las ayudas directas de la PAC en la caja verde del Acuerdo de Marrakech. Para evitar una condena general, ya se han producido los primeros movimientos para explicar que el problema no es general para toda la Unión Europea sino su aplicación en España. Francia por ejemplo tiene ya dos únicas regiones, la Francia continental y Córcega. Alemania tiene una tasa plana para todo el país. Grecia tiene 3, cultivos herbáceos, cultivos leñosos y pastos.

Alan Matthews (2019) ya lo señalo en su momento pero noticias de prensa recientes lo han confirmado, cuando hablan de la necesidad de tener en cuenta las "regiones tabaqueras ${ }^{10}$ " $\mathrm{o}$ de "la premura en la aprobación de esta normativa ha impedido a los agricultores planificar sus cosechas"11. Sin duda son

\footnotetext{
${ }^{9}$ https://www.wto.org/english/tratop e/dispu e/cases e/ds577 e.htm

${ }^{10}$ https://navalmoral.hoy.es/region-tabaquera-convergencia-20210224213954-nt.html

${ }^{11}$ https://www.latribunadeciudadreal.es/noticia/Z826642F8-0FC7-845DED6B4510FB50D269/202101/Asaja-pide-una-transicion-mas-moderada-en-la-convergencia
} 
argumentos de oro que los Estados Unidos utilizaran en sus futuras comunicaciones a los miembros del panel.

Esto explica el carácter bastante explicito que utiliza la Comisión en sus " recomendaciones" del 18 de diciembre de 2020 para que sus futuros planes estratégicos de la PAC cumplan con los requisitos del " Pacto Verde " y, en particular, las Estrategias Europeas "De la Granja a la Mesa " y "Biodiversidad ". En contraste con el lenguaje diplomático habitual en este tipo de documentos, el texto pide para la convergencia interna avances significativos, distribuir las ayudas en grupos homogéneos de territorios y eliminar el vínculo con las referencias históricas. Ello representa una enmienda a la totalidad a la "regionalización" española.

\section{Conclusión provisional}

El gobierno español se encuentra ante una tarea difícil, que viene a sumarse a la complejidad ya de por si grande de preparar, consensuar y conseguir que Bruselas apruebe su Plan Estratégico nacional. Tiene que "avanzar significativamente" en 3 convergencias internas: las diferencias entre las ayudas unitarias dentro de cada una de las 50 regiones existentes; la disminución del número de regiones y la reducción de las diferencias entre los valores medios de las regiones finales. No se trata por lo tanto de implantar una "tarifa plana".

El acuerdo de la PAC actual tenía como referencia en el tiempo el año 2019. No hubo ninguna indicación de lo que debería acontecer en los años siguientes porque nunca se pensó en la posibilidad de tener que prolongar dos años más la PAC actual por falta de acuerdo, aunque no cabe dudar que los procesos de convergencia debían seguir. De hecho, el acuerdo presupuestario ya aprobado tanto por el Consejo como el Parlamento incluye ya los siguientes pasos de la convergencia interna.

El gobierno del estado ha aprobado un Real Decreto el 26 de enero $2021^{12}$ que avanza significativamente en la primera de las convergencias mencionadas, para los dos años de la transición hacia la nueva PAC, dejando para el 2023 las dos siguientes que representarían cabios de gran calado que deben sr negociados e incluidos en el Plan Estratégico nacional.

Este Real Decreto ha recibido una muy mala acogida en particular en Andalucía, Comunidad autónoma donde se ha producido un frente común entre la Consejería y las distintas organizaciones profesionales agrarias. Por esperado, e inevitable, que sea este primer paso, es verdad que afecta en particular a unos sistemas productivos que habían acumulado unas "mochilas históricas" consecuentes. Por razones de espacio, solo abordaremos aquí 3: el cebo de terneros, el tabaco y los colonos del valle del Guadalquivir.

El cebo de terneros tenía inicialmente que haber recibido el mismo trato que la ganadería porcina y aviar, ha disfrutado durante más de 20 años de una situación privilegiada que se acerca a su fin. En cuanto a los productores de tabaco, la lógica (desde el año 2003) del desacoplamiento es que si el cultivo no es atractivo para el agricultor sea sustituido por otros, lo que ya ha acontecido en muchas zonas. Aunque pueda tener toda su lógica económica y social, es impensable políticamente la concesión de una ayuda acoplada para un producto cuyo consumo está en la línea de mira de las autoridades sanitarias

En el valle del Guadalquivir, los colonos tienen explotaciones familiares de dimensiones pequeñas o medianas y han compensado su hándicap estructural con producciones que generaron una mayor renta por hectárea como pueden ser el algodón, la remolacha, la alfalfa o el tomate para industria. Dos instrumentos pueden claramente ayudar a aliviar la situación, la ayuda redistributiva para las primeras hectáreas de la explotación y unas ayudas acopladas bien diseñadas. Sin duda, este problema específico identificado (que seguramente no será el único) merece ser profundizado tanto para el segundo año de la transición, el 2022, como para e nuevo régimen que empiece a partir del 2023.

\section{Bibliografía}

${ }^{12}$ https://www.boe.es/diario boe/txt.php?id=BOE-A-2021-1131 
European Commission (EC, 2015): Direct Payments: the Basic Payment Scheme from 2015 - Convergence of the value of payment entitlements ('Internal Convergence') https://ec.europa.eu/info/sites/info/files/foodfarming-fisheries/key_policies/documents/internal-convergence_en.pdf

European Commission (EC, 2020): Commission recommendations for Spain's CAP strategic plan https://eur-lex.europa.eu/legal-content/EN/TXT/?uri=CELEX\%3A52020SC0374

Matthews, A. (2019): The looming EU- US WTO Spanish ripe olives dispute http://capreform.eu/thelooming-eu-us-wto-spanish-ripe-olives-dispute/

Miranda, F. (2021): "Es comprensible que quien recibió derechos de pago PAC de alto valor en el pasado quiera que la convergencia interna se dilate lo máximo posible. Agronegocios nº751 (3-4)

Ruiz, J. (2019): Distribution of direct payments: the peculiar case of the Spanish model http://capreform.eu/distribution-of-direct-payments-the-peculiar-case-of-the-spanish-model/ 